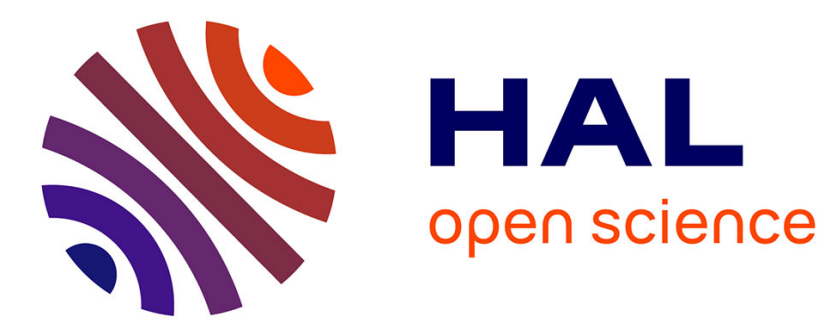

\title{
Flexibility in Lean Mixed Model Assembly Lines
}

Natalia Svensson Harari, Christer Osterman, Jessica Bruch, Mats Jackson

\section{To cite this version:}

Natalia Svensson Harari, Christer Osterman, Jessica Bruch, Mats Jackson. Flexibility in Lean Mixed Model Assembly Lines. IFIP International Conference on Advances in Production Management Systems (APMS), Sep 2014, Ajaccio, France. pp.224-231, 10.1007/978-3-662-44733-8_28 . hal01387184

\section{HAL Id: hal-01387184 \\ https://hal.inria.fr/hal-01387184}

Submitted on 25 Oct 2016

HAL is a multi-disciplinary open access archive for the deposit and dissemination of scientific research documents, whether they are published or not. The documents may come from teaching and research institutions in France or abroad, or from public or private research centers.
L'archive ouverte pluridisciplinaire HAL, est destinée au dépôt et à la diffusion de documents scientifiques de niveau recherche, publiés ou non, émanant des établissements d'enseignement et de recherche français ou étrangers, des laboratoires publics ou privés.

\section{(c)(1)}

Distributed under a Creative Commons Attribution| 4.0 International License 


\title{
Flexibility in Lean Mixed Model Assembly Lines
}

\author{
Natalia Svensson Harari ${ }^{1,2}$, Christer Osterman ${ }^{1,3}$, Jessica Bruch ${ }^{1}$, and Mats Jackson ${ }^{1,2}$ \\ ${ }^{1}$ Mälardalen University, Department of Product Realization, Eskilstuna, Sweden \\ \{natalia.harari, jessica.bruch, mats.jackson\}@moh.se \\ ${ }^{2}$ VolvoCE, Manufacturing Research, Eskilstuna, Sweden \\ \{natalia.svensson. harari, mats. jackson\} @volvo.com \\ ${ }^{3}$ Scania CV AB, TD, Södertälje, Sweden \\ christer.ostermanescania.com
}

\begin{abstract}
The purpose of the research presented in this paper has been to characterize flexibility in lean mixed model assembly lines through exploring mechanisms used to achieve flexibility. The study combines a literature review and a multiple case study in two manufacturing companies. Scenarios of volume, mix and operation flexibility, as well as flexibility to introduce or remove products were studied. The results showed that to achieve flexibility related to these scenarios other kinds of flexibilities were used. Common mechanisms to achieve flexibility have been found in the two cases. A characterization of mixed model assembly lines regarding flexibility will be discussed.
\end{abstract}

Keywords: Mixed model assembly lines, lean, flexibility.

\section{Introduction}

Due to changing demands and shorten product life cycles, manufacturing companies deal with strategies to handle a variety of products and production volumes in their assembly systems. Assembly systems in the automotive industry in Sweden today are usually semi-automated mixed model lines where different product variants are assembled and operators are in charge of performing most of the assembly processes. Influenced by lean strategies, approaches to level production volumes and rationalization through elimination of the so called non-value-adding work are used. Different dimensions of flexibility have been described in the literature and difficulties of generalizing flexibility measures may be encountered [1]. Manufacturing settings are usually used when defining flexibility characteristics, and more information about them in assembly systems is needed beyond the efforts on describing Flexible Assembly Systems. These have been most of the times referred to as automated systems. The purpose of the research presented in this paper has been to characterize flexibility in lean mixed-model assembly lines (MMAL) through exploring mechanisms used to achieve flexibility taking into account the constituents of the assembly system described in the literature: human system, technical system, material handling system, information system and building and premises [2]. 


\section{Frame of References}

\subsection{Flexibility Dimensions and Measures}

There are differences in meanings regarding flexibility as well as variation in perspectives specially when broken down into its dimensions, elements, and measures [3]. To characterize flexibility, Upton (1994), presented a framework of flexibility management regarding dimensions, time horizon and elements. Dimensions concern the required flexibility and need to change. Time horizon is related to the timeframe in which the change will occur. Elements of flexibility concern range, uniformity or mobility [4]. Dimensions of flexibility have been described by different authors such as Browne et al. (1984), Sethi and Sethi, (1990), and Gupta and Somers (1992) [5, 6, 7]. Koste and Malhotra, (1999), proposed a theoretical framework to analyze flexibility dimensions where 10 dimensions of flexibility were considered; Machine flexibility (number and variety of operations the machine can perform), Labor flexibility (number and variety of operations/task that workers can perform), Material handling (number of paths and variety of material), Routing flexibility (number of products with alternate routes and extend of variation between routes), Operation flexibility (number of products with alternate sequencing plans and variety of plans), Expansion flexibility (number and variety of expansions), Volume flexibility (extend of change and degree of fluctuations in output level), Mix flexibility (number and variety of products that can be produced), New product flexibility (number and variety of products that can be introduced), Modification flexibility (number and variety of product modifications), all of them without incurring in high transition penalties or large changes in performance outcomes [1]. The elements of flexibility have been then defined by them as; Range-Number (number of tasks, products, etc), Rangeheterogeneity (differences in task, products, etc.), Mobility (transition penalties - time, cost, effort) and Uniformity (similarity of performance outcomes such as quality, cost, time) [1]. Based on Atkinson, (1984) and Allvin and Aronsson, (2013) some definitions of labor flexibility are further described; Functional flexibility (capacity of the job and the organization of work such as teamwork. It implies a reorganization and conversion of the operators to new work tasks. These methods are used for practical and immediate purposes), Numerical flexibility (adaption of the workforce to the changes in production not related to the performance of work. Some examples of this are: temporary employment, outsourced personnel and staffing agencies.), Temporal and financial flexibility (adjusting working time or labor cost. It could also include variable salaries.) $[8,9]$.

\subsection{Lean Mixed-Model Assembly Lines}

The necessity of using the same equipment and line for different models was one of the driving forces behind the development of the Lean methods and principles [10]. In a Lean assembly line the Takt time is used to organize and balance the line. When producing a mix of models, some degree of leveling is necessary [11]. Even when the cycle-time of each particular model could be different, the overall takt time remains 
the same. This can be accomplished with internal buffers acting as de-couplers in the process but preferable with set up time reduction [12]. Just-In-Time (JIT) is a concept where the parts used in assembly are paced using a Kanban system to create pull in production and avoid waste [13] where the upstream process only produces as much as the downstream process consumes. The pull principle requires consistent leveling to reduce variation in demand. A Kanban system has several aspects and can be used to regulate the material flows as well as the assembly orders [14]. Standardized work connects resource efficiency with flow efficiency through the balancing of the process. Standardized work is connected to standard time [15] thus reducing variation in the assembly process. To handle different work content that products could have, solutions such as variation of workers in assembly, utilizing sub assembly lines, and concentrating imbalances to particular points of the assembly process are used [15]. Regarding setup times, different products require different fixtures. Changing can take time, reducing the flow efficiency of the process. Commonality of interfaces, generalized tools and fixtures and various SMED principles are used [12]. Planning and mixing rules are used to handle variation of customer demands. Problem solving and continuous improvement activities are carried out.

\section{$3 \quad$ Methods and Techniques}

The research method was based on a multiple-case study design as described by Yin (2014) [16]. It was a quali-quantitative and participative study. The literature review gave input to the design of the research study. The study focused on flexibility of volume, mix, operation and flexibility to introduce new products and remove existing ones. The assembly system was analyzed from all its constituents: human system, technical system, material handling system, information system and building and premises [2]. The study was conducted in two Swedish manufacturing companies, defined as Case A and Case B producing the same component in MMALs with production systems based on lean principles. The study was conducted by two researchers from June 2013 until April 2014. The design of the data collection protocol consisted of: Informed consent, background information of the participant, recorded semi-structured interviews, observations protocol. A pilot study was developed at the same companies but in different assembly areas. Active observations were made at the lines. In total 11 semi-structured interviews of around 1 hour were conducted to production managers, production technicians and logistics managers. The interviews were developed by function, conducted in Swedish, recorded and transcribed for reliability. The analysis of the data used the approach of Miles and Huberman, (1994) [17]. The collected data and transcriptions went through data reduction process and analysis supported by the frame of references. The results of each case were then used to draw cross-case conclusions. 


\section{$4 \quad$ Empirical Findings}

The study concerned the assembly of a specific component referred as component $X$, $\mathrm{Y}$ and $\mathrm{Z}$. Three assembly lines were studied in Case A which assembled $\mathrm{X}, \mathrm{Y}$ and $\mathrm{Z}$ according to the final products. Case $\mathrm{B}$ had different assembly lines for $\mathrm{X}, \mathrm{Y}$ and $\mathrm{Z}$ for different final products. Two assembly lines were studied in Case B. Both companies worked with modularization in their products, and mutual processes, tools, infrastructure, resources between models were used. Case B had a modular system established at the company. Both worked with semiautomatic hand-tools connected to andon systems and also customized fixtures and tools. Teams of 5 or 7 operators and 1 team leader worked along the lines. One or two operators worked in parallel by station depending on the product variant. Operators were employed by the company or outsourced in permanent and temporal terms. Stairs salary systems related to the competence were used. The takt time of the cases had differences. Case A used stop and go AGV's systems. Operators rotated according to a schedule. Training and education of new operators was done in the line by the team leader. The company used a centralized material handling area. Some parts were delivered using poka-yoke solutions. Around 6 to 14 variants were assembled. The number of operators per line varied from 7 to 15 , and the main lines had 3 or 4 stations. Case B used a continuous moving overhead conveyor as well as robots at some stages and elevators to transport the parts. Operators rotated every half an hour. Training and education of new operators was done in a separate area. Different material handling areas were dedicated for each line. Kits and moving racks beside the line were used. More than 100 variants were assembled. The number of operators per line varied from 70 to 105 and the main lines had 20 to 30 stations plus internal buffers and one area for special products.

\subsection{Mechanisms to achieve flexibility}

Volume Flexibility. Related to the capacity of the system, the cases analyzed scenarios of volume change followed by a decision making process. The balance of the line was a determining factor in the decisions. According to the magnitude of the volume change, they usually started with changes in shift-forms and working times, increasing or decreasing the number of employees avoiding possible changes in the current takt time and rebalancing the line, until the point when the capacity was exceeded and investments were needed. Logistics needed to adapt its capacity according to assembly. When assembly volumes decreased, they tried to maintain the same takt time using strategies such as takt holes. One consequence of decreasing personnel was that competence needed was lost also for scenarios when volume increases again. Case B had agreements with the Union concerning flexible working times and time banks for periods of increase or decrease of the based takt time. Mechanisms used to achieve volume flexibility are shown in Figure 1. 


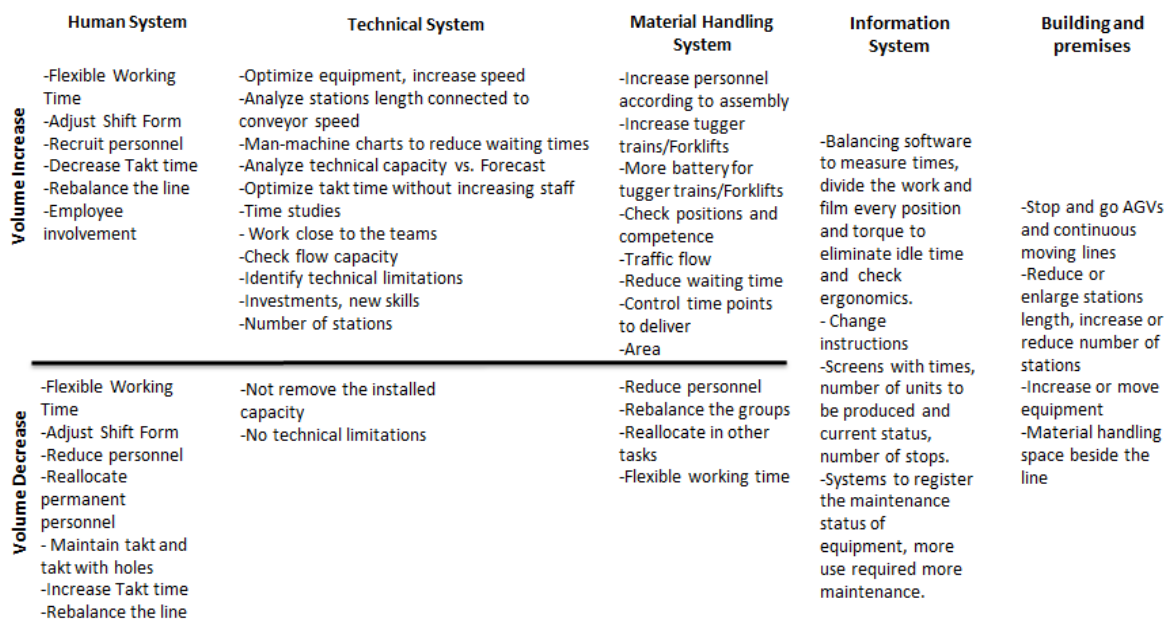

Fig. 1. Mechanisms used to achieve volume flexibility and its relation with the assembly system constituents.

Mix and Operation Flexibility. Both companies delivered a variety of products. Assembly shared resources and processes for a variety of products. Alternate areas were used for products with high differences in work content in Case B. About operation flexibility, an assembly plan containing the variety of models was delivered in the first positions at the line specifying the sequence of models to be assembled. Some distinctions should be made in relation to the definition of sequence in assembly. Sequence could be referred as the sequence of processes in which the products are assembled, but sequence is also referred to as the order in which the different models will be assembled during the shift connected to customer orders and balance in the line. Mechanisms used to achieve product mix and operation flexibility are shown in Figure 2.

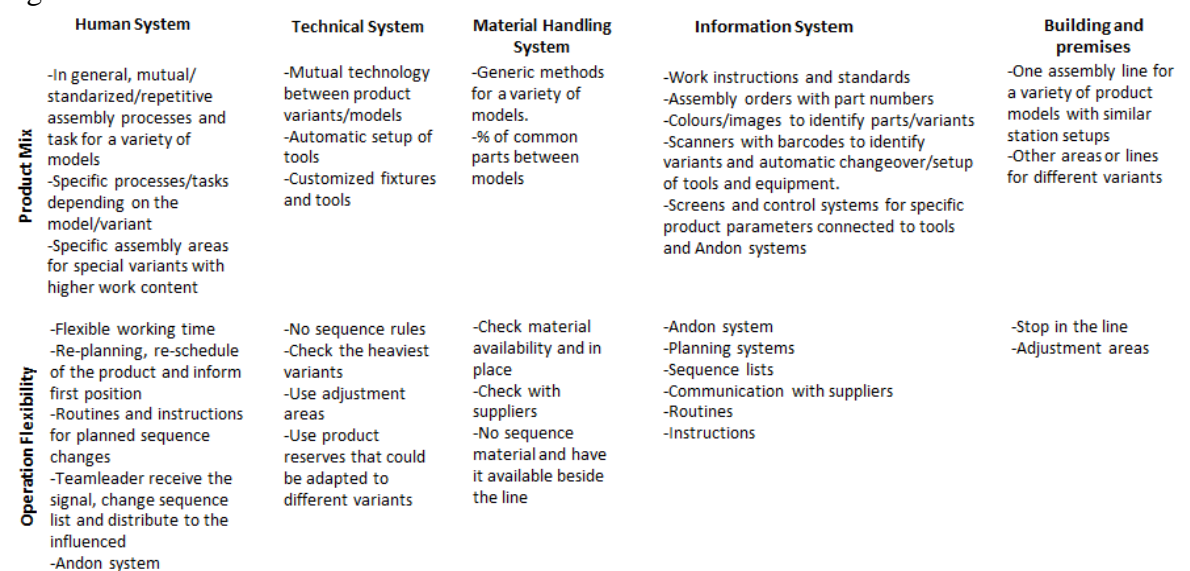

Fig. 2. Mechanisms used to achieve operation and product mix flexibility and its relation with the assembly system constituents. 
New Product and Removal of Existing Product Flexibility. The introduction of new products was considered a complex project in both companies. Challenges were related to cooperation between product design and assembly upon the technical implications from both perspectives and e.g. due to ergonomics. The companies analyzed the design of new products in relation to the existing ones to make possible the use of e.g. existing technology and resources. However, evaluations of possible modifications that did not destabilize the current assembly were also made as well as due to a potential need of building new assembly areas. Involvement of different levels of the organization was mentioned to be needed, due to possible new methods, instructions, times, technology, etc. Removal of existing products required the participation of preparation areas in coordination with assembly and logistics. Mechanisms used to achieve new product and removal of existing ones are shown in Figure 3.
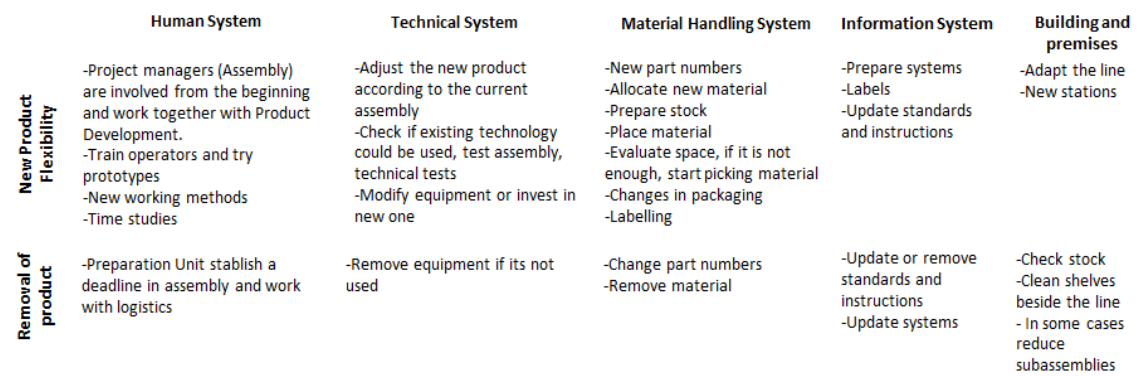

Fig. 3. Mechanisms used to achieve new product/removal of existing products flexibility and its relation with the assembly system constituents.

\section{$5 \quad$ Analysis}

The cases illustrate mechanism used to achieve flexibility and its relation with the assembly system constituents. To achieve volume, mix and operation flexibility and new product/removal of existing products flexibility, other flexibilities have been used. An overview of these results is shown in Figure 4.
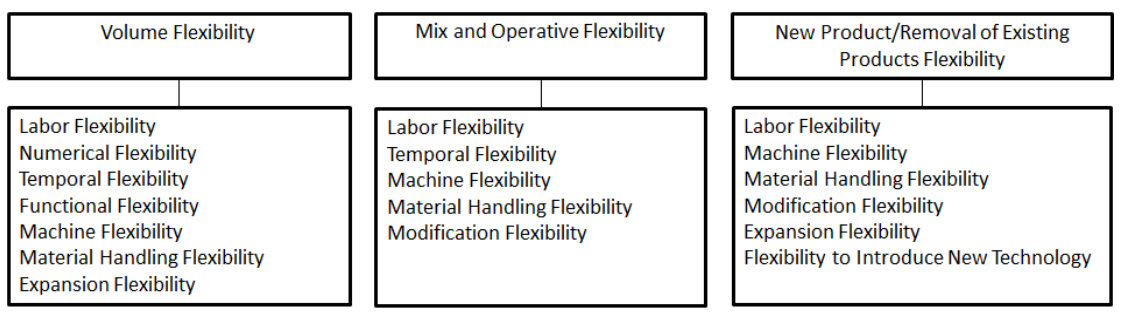

Fig. 4. Overview of identified flexibilities

According to the results, the timeframe in which those mechanisms were used varied. Different kinds of labor flexibility such as functional, numerical and temporal took 
place in shorter periods of time compared to expansion flexibility or flexibility to introduce to new products due to e.g. investments. Already mentioned in the literature, introduction of new product flexibility could be related to flexibility to introduce new technology [18]. Routing flexibility is not really used in MMAL; instead the assembly sequence is taken into account. When differences are considerable between products, they are clustered or other assembly areas are used. The results suggest that the flexibility of a MMAL is related to its design and the options it has to be flexible are until some extent circumscribed by it.

Even though one of the cases had a modular system established at the company, common mechanisms to achieve flexibility were found between the cases. However, differences exist e.g. in the number of models assembled. This suggest that modularity could until some extend facilitate the introduction of new products, but other capabilities are still needed such as cooperation between assembly and product design, appropriate technical evaluations, involvement of different levels of the organization, and infrastructure to test the new designs.

Regarding flexibility elements described in the frame of reference by Koste and Malhotra (1999) [1] and its relation to MMAL, it was identified that concerning rangenumber and range-heterogeneity various product models were assembled which until some extend shared assembly processes, tasks, information, parts and equipment. The products can be customized, meaning that still differences between models could exist. Regarding mobility, methods are used to reduce setup times, and there could be short tool change over times between models, some of them adjusted automatically by scanning product barcodes. About uniformity, the models are expected to follow mutual and standardize assembly processes through all the stations. The models are delivered following the same takt time. To balance the line, work content measured in time is divided in similar proportions between stations for the variety of models. The products passed through quality control checks, sometimes one station at the end of the line was also dedicated to this purpose. Information systems are used to control and secure uniformity in quality and time.

\section{Conclusion}

Flexibility is a complex definition and different perspectives exist. A characterization of lean MMALs has been presented through analysing mechanisms to achieve flexibility in two cases and their relations to the constituent parts of the assembly system. Even though this study identified mechanisms of flexibility in assembly system related to volume, mix and operative flexibility and new product/removal of products flexibility, it has been shown that to achieve those kinds of flexibilities other dimensions of flexibility are also used. The timeframe by which these mechanisms are used vary. Regarding the elements of flexibility, lean MMALs are focused on delivering a wide range number and heterogeneity of products models by using common resources and processes. Different methods are used in regard of mobility, in order to reduce setup times and change overs. Uniformity is achieved by e.g. takt times, quality controls and standardization. By characterizing flexibility in MMALs taking into account 
the constituents of the assembly system, it could possible to better understand and evaluate its implications as well as its relation to the assembly system design from a holistic perspective.

Acknowledgment. The authors gratefully acknowledge the contributions from all the participants in the case study companies. This research work has been funded by the Knowledge Foundation within the framework of the INNOFACTURE Research School and the participating companies, and Mälardalen University. The research work is also a part of the initiative for Excellence in Production Research (XPRES) which is a joint project between Mälardalen University, the Royal Institute of Technology, and Swerea. XPRES is one of two governmentally funded Swedish strategic initiatives for research excellence in Production Engineering.

\section{References}

1. Koste, L.L., Malhotra, M.K.: A Theoretical Framework for Analyzing the Dimensions of Manufacturing Flexibility. Journal of Operations Management 18.1, 75-93 (1999)

2. Rösiö, C.: Supporting the Design of Reconfigurable Production Systems. PhD Thesis, Mälardalen University, Eskilstuna (2012)

3. D'Souza, D.E., Williams, F.P.: Toward a Taxonomy of Manufacturing Flexibility Dimensions. Journal of Operations Management. 18.5, 577-593 (2000)

4. Upton, D.: The Management of Manufacturing Flexibility. California management review. 36.2, 72-89 (1994)

5. Browne, J., Dubois, D., Rathmill, K., Sethi, S.P., Stecke, K.E.: Classification of Flexible Manufacturing Systems. The FMS Magazine, 2.2, 114-117 (1984)

6. Sethi, A.K., Sethi, S.P.: Flexibility in Manufacturing: A Survey. International Journal of Flexible Manufacturing Systems, 2.4, 289-328(1990)

7. Gupta, Y.P., Somers, T.M.: The Measurement of Manufacturing Flexibility. European Journal of Operational Research. 60.2, 166-182 (1992)

8. Atkinson, J.: Manpower Strategies for Flexible Organizations. Personnel Management. 2831 (1984)

9. Allvin, M., Aronsson, G.: Flexibility, Boundarylessness and the Strategies of Work. 420435. In Sandberg, A.: Nordic Lights: Work, Management and Welfare in Scandinavia. SNS Förlag, Falun (2013)

10. Ohno, T.: Toyota Production System, Beyond Large-Scale Production, CRC Press, (1988)

11. Wilson, L.: How to Implement Lean Manufacturing, McGraw-Hill, (2010)

12. Shingo, S.: A Revolution in Manufacturing: The SMED System, CRC Press, (1985)

13. Ohno, T., Mito, S.: Just-In-Time, For Today and Tomorrow, Productivity Press, (1988)

14. Dennis, P.: Lean Production Simplified, Productivity Press, (2002)

15. Baudin, M.: Lean Assembly, CRC Press, (2002)

16. Yin, K.R.: Case Study Research: Design and Methods. SAGE, USA (2014)

17. Miles, M.B., Huberman, A.M.: Qualitative Data Analysis: An Expanded Sourcebook. UK:SAGE, London (1994)

18. Ohlager, J.: Produktionsstrategier, TPPE50, Institutionen för Produktionsekonomi, Linköpings Tekniska Högskola, Linköping (1996) 